\title{
PROBLEMATIZAÇÃO DO CONTEÚDO-METODOLOGIA COMO ESTRATÉGIA PARA FORTALECER O DIÁLOGO-PROBLEMATIZADOR
}

Elena Maria Mallmann

Emallmann@mail.ufsm.br

Fábio da Purificação de Bastos

fbastos@ce.ufsm.br

Felipe Martins Müller

felipe@inf.ufsm.br

\section{RESUMO}

Sistematizamos as atividades de ensino-aprendizagem investigativa desenvolvidas na disciplina Didática I da Física (MEN 500) do curso de licenciatura em Física - Diurno da Universidade Federal de Santa Maria (UFSM). Inicialmente localizamos o contexto e os sujeitos envolvidos na prática dialógico-problematizadora realizada no curso de formação escolar de professores. Apresentamos documentos oriundos das tarefas extra-classe (TE) implementadas num Ambiente Multimídia para Educação Mediada por Computador na Perspectiva da Investigação-ação (AMEM), disponível em: $<$ http://amem.ce.ufsm.br>. A partir desses, enfatizamos o quadro analítico gerado diante da implementação dos procedimentos didático-metodológicos investigativos ao longo de um semestre letivo. Localizamos os inéditos-viável e situações-limite durante a problematização do conteúdo-metodologia, como estratégia para fortalecer o diálogo-problematizador numa disciplina que hibridiza conteúdos escolares de Física e metodologia do ensino de Física.

\section{ANÁLISE DO CONTEXTO}

\subsection{Descrição do contexto}

O contexto do qual falamos e implementamos nossas atividades é o curso de licenciatura em Física da UFSM. Trabalhamos com os estudantes da disciplina Didática I da Física, a qual corresponde ao sexto semestre. Nossas aulas foram orientadas por temáticas que envolveram Alfabetização Científico-Tecnológica (ACT) nos eixos Didática da Física, Resolução de Problemas, Educação DialógicoProblematizadora (EDP) e Investigação-ação Escolar (IAE). Priorizamos temáticas como: a) transposição didática; b) políticas públicas educacionais para formação de professores da educação básica; c) parâmetros curriculares nacionais para o ensino médio; d) redes conceituais; e) momentos pedagógicos dialógicos-problematizadores 
(MPDP); f) ensino-investigativo; g) Meios Tecnológico-comunciativos (MTC) e; h) Tarefas Extra-Classe (TE).

\subsection{Constituição do grupo de trabalho}

O grupo de trabalho era constituído por 24 estudantes matriculados, o professor doutor responsável pela disciplina, um mestrando do PPGE da UFSM em fase de elaboração da dissertação, um doutorando do Programa de Pós-Graduação em Educação da UFSC e uma mestranda do PPGE da UFSM realizando atividades de docência orientada.

Além das aulas em que participavam estudantes e professores elencamos tarefas como: a) programação semanal das aulas e das tarefas extra-classe (TE) e b)realização e monitoramento das TE no Ambiente Multimídia para Educação Mediada por Computador (AMEM), disponível em: <http://amem.ce.ufs.br>. Além disso, mantivemos a Atividade de Colaboração (AC) no AMEM, na qual disponibilzamos previamente programação para próxima aula e a indicaçãod as bibliografias.

\subsection{Identificação e descrição da temática que investigamos ativamente}

Diante do universo de constantes avanços científico-tecnológicos, produzidos ao longo da história da humanidade, temos nos preocupado com as atividades curriculares-disciplinares de Ciências Naturais e suas Tecnologias (CNT) desenvolvidas nos cursos de formação de professores. Tendo em vista o caráter evolutivo desses conhecimentos, a renovação dos conteúdos culturais/escolares que perpassam os cursos de licenciatura se torna tarefa urgente, uma vez que o trabalho escolar nas unidades da educação básica é resultado concreto da trajetória escolar vivenciada na formação inicial.

As fragilidades na formação em CNT, nos cursos de Pedagogia, por exemplo, traz como resultado imediato que as atividades curriculares, realizadas pela maioria dos professores no ensino fundamental sejam constituídas essencialmente pela 
alfabetização em língua portuguesa e matemática. Quando atividades de ciências são propostas, elas se limitam, muitas vezes, às programaçoes dos livros didáticos.

Por outro lado, os currículos das licenciaturas com habilitações específicas, como é o caso da Física, intensificam muito a preparação dos estudantes em termos dos conhecimentos científico-escolares de cada área. Dessa forma, não priorizam a formação em termos dos conhecimentos pedagógicos e didático-metodológicos necessários para atuação do profissional da educação.

A partir disso, nossa preocupação ficou tematizada pela hibridização conteúdometodologia na disciplina Didática I da Física. A definição desse foco possibilitou estabelecermos interfaces com o projeto de mestrado da estudante que estava realizando atividades de docência orientada na disciplina. O foco central desse projeto, por sua vez, gira em torno do Acoplamento entre as aprendizagens presencial e a distância através do monitoramento eletrônico da TE no AMEM .

\section{FASE DA PROGRAMAÇÃO}

\subsection{Delimitação do problema}

As atividades desenvolvidas na disciplina sempre mantiveram o recorte na organização didático-metodológica do ensino, aprendizagem e investigação na formação escolar inicial de professores de Física. Desse modo, as tarefas que realizamos ao longo das aprendizagens na sala de aula e a distância (TE) contribuíram essencialmente na investigação da preocupação temática.

Para melhor orientarmos essa investigação construímos o que chamamos de matriz dialógico-problematizadora (MDP) segundo as orientações de Kemmis e Mactaggart (1988). Elaboramos dezesseis questões de pesquisa numa matriz composta de quatro colunas por quatro linhas. Relacionamos os quatro elementos: professores, estudantes, tema de estudo e contexto entre si e com todos os outros. Essas questões orientam o processo de ensino-aprendizagem investigativo nas aulas, ao longo do semestre. A seguir, apresentamos: a) a definição dos quatro elementos que 
consituíram a MDP da disciplina de Didática I da Física e b) dois exemplares de questões retiradas da matriz :

\section{a) elementos da MDP}

Professores: Professor-doutor da disciplina MEN 500 da UFSM, doutorando da UFSC e dois mestrandos em educação da UFSM

Estudantes: Estudantes matriculados na MEN 500 do curso diurno de licenciatura em Física

Tema de Estudo: Didática da Física, Resolução de Problemas e Investigação-ação Escolar

Contexto: Formação Inicial de Professores de Física na UFSM.

\section{b) dois exemplares}

Ao relacionarmos o elemento [A] Professores da primeira coluna com o elemento [1] Professores da primeira linha elaboramos a questão [A1]:

Como os professores de MEN 500 têm priorizado a resolução de problemas, na perspectiva da construção formativa continuada da prática de ensino-investigativa? Já ao relacionarmos o elemento [D] Contexto da quarta coluna com o elemento [2] Estudantes da segunda linha elaboramos a questão \{D2]:

A hibridização conteúdo-metodologia, na disciplina de MEN 500 é compreendida pelos estudantes, durante a atividade de resolução de problemas de física?

A1 e D2 são apenas dois exemplares escolhidos entre as questões (A1, A2, A3, A4 - B1, B2, B3, B4 - C1, C2, C3, C4 - D1, D2, D3, D4) que compõem a MDP. Para cada aula escolhemos uma delas tendo em vista a orientação de nossas programações e, principalmente, os registros do que funcionou ou não funcionou nas aulas.

\subsection{Programação de estratégias}

Nesse trabalho, utilizamos como guia para operacionalização da ação escolar os MDP que são três: a) Desafio Inicial (envolvemos ativamente os estudantes na resolução de um desafio referente ao recorte temático da aula); b) Melhor Solução Escolar no Momento (problematizamos as visões de mundo iniciais dos estudantes tensionandoas frente ao conhecimento científico escolar) e c) Desafio Mais Amplo (é o momento 
em que propormos um novo desafio para que os estudantes operacionalizem os principais conceitos abordados).

A organização, disponibilização, realização e monitoramento das TE e AC no AMEM foi a estratégia prioritária de investigação da prática escolar desenvolvida. $A$ docência investigativa abrangia tanto o espaço da sala de aula quanto o das atividades a distância, à medida que inovamos estratégias desafiadoras de monitoramento eletrônico das TE no AMEM.

O monitoramento, como componente do trabalho docente, permite construírmos avanços na nossa estratégia investigativa via três momentos pedagógicos didáticometodológicos. Pois os resultados gerados através da investigação das atividades que os estudantes realizaram extra-classe permite fortalecermos cada vez mais o diálogo-problematizador nas aulas.

A seguir apresentamos dois exemplares das estratégias de trabalho escolar docente

e discente que programamos para cada aula e TE ao longo do semestre:

\section{$8^{a}$ AULA - Livro Didático - 21/11/2002}

[30 min] DI - Assistir teleaula 50 de Física do TeleCurso 2000 e identificar, em duplas, os momentos pedagógicos (revisar o conceito de momento de pedagógico).

[60 min] MSEM1 - Analisar, em duplas, o texto da aula 50 de Física do TeleCurso 2000), em termos de unidade, tópico, núcleo e metas (destacar que o material didático - teleaula e texto - são elaborados por professores).

[30 min] MSEM2 - Elaborar, em trios, a RC da aula 50 de Física do TeleCurso 2000 e apresentar para o grupo.

[30 min] MSEM3 - Analisar a proposta didático-metodológica da aula 50 de Física do TeleCurso 2000 no escopo da EJA.

[30 min] Problematizar a tarefa extra-classe Observação 2.

[30 min] Discutir possíveis mudanças no Contrato Didático e Calendário Escolar.

TE: Analise, tendo em vista a formação de professores de Física, as informações contidas no endereço http://www.telecurso2000.org.br/tele2k/scripts/tc2000.asp, 
tomando como critérios a organização didático-metodológica dos materiais e as atividades de resolução de problema.

\section{9a AULA - Políticas Públicas Educacionais - 06/12/2002}

[30 min] DI - Escreva as competências e habilidades necessárias na formação escolarinicial dos professores de Física.

[30 min] MSEM - Destacar no texto das Diretrizes Curriculares Nacionais para a Formação de Professores da Educação Básica (DCNFPEB) o núcleo central da proposta e representar no quadro o esquema hexaédrico das competências

[30 min] MSEM - Destacar no texto das Diretrizes Curriculares Nacionais para os Cursos de Física (DCNCF) o núcleo central da proposta e representar no quadro sua estrutura modular.

[30 min] MSEM- Destacar na estrutura modular dos cursos de Física as competências essenciais. 30 min MSEM- Indicar as incoerências entre as DCNCF e a Resolução de 19/02/2002.

[30 min] DA - Diálogo sobre as implicações da não implementação da Lei Federal, na formação escolar-inicial de professor de Física.

[30 min] Diálogo entre os envolvidos na disciplina de MEN500.

TE: Analise a formação escolar inicial do Físico-educador tendo em vista as competências e habilidades a serem desenvolvidas em Física no ensino médio, baseando-se nos Parâmetros Curriculares Nacionais -- Ensino Médio (Parte III -Ciências da Natureza, Matemática e suas Tecnologias, p22-29). (Este texto dos PCN está disponível na biblioteca do AMEM, assunto políticas públicas educacionais e no xerox do CE/UFSM).

\section{3, PROCESSO DE DESENVOLVIMENTO}

\subsection{Implementação da ação}

Implementamos nossas ações escolares nas aulas sempre obedecendo as programações que havíamos organizado. O mesmo podemos dizer das outras atividades que realizamos na disciplina, uma vez que sempre eram pautadas pelo 
calendário previamente agendado entre professor responsável, docente orientada e estudantes matriculados. Mesmo nas semanas em que os estudantes realizavam as observações nas escolas mantínhamos TE no AMEM porque a responsabilidade pelo processo escolar na disciplina ainda continuava sendo dos professores. Dessa forma, também, continuávamos mantendo o registro escrito das tarefas realizadas pelos estudantes e o monitoramento eletrônico das mesmas.

\subsection{Recolhimento dos dados}

Recolhemos nossos dados ao longo das aulas, registrando as observações num caderno em que já tínhamos explicitado a programação. Também no AMEM dispomos de um espaço eletrônico para armazenarmos no banco de dados os registros de cada aula implementada. Como as respostas de cada TE e AC realizadas pelos estudantes ficam registradas no AMEM essas também servem de parâmetros para nossas análises e reflexões.

\section{CONSIDERAÇÕES FINAIS}

Ao longo do trabalho escolar de docência investigativa na disciplina Didática I da Física do curso de licenciatura em Física- Diurno da UFSM verificamos: potencialidades investigativas no ambiente de ensino-aprendizagem para internet (AMEM); situações-limite, principalmente, dos estudantes envolvidos; necessidade de fortalecimento das aprendizagens em torno das tarefas extra-classe (TE) e meios tecnológico-comunicativos (MTC).

Mesmo se tratando de um curso de formação de professores com habilitação específica em Física, ressaltamos que a MEN 500 é uma disciplina que envolve a obordagem da organização didático-metodológica do trabalho escolar. Por isso, tornou-se possível tratarmos de conceitos-chave como MTC e TE, aliando-os aos diálogos em torno da resolução de problemas, políticas públicas educacionais, modelos didáticos, investigação-ação escolar, educação dialógico-problematizadora, entre as outras temáticas que abordamos. 
Esse espaço foi priveligiado para investigação e problematização da preocupação temática definida para a disciplina. Ao mesmo tempo, possibilitou articulações com a temática do projeto de mestrado. Ao tratarmos da investigação do acoplamento entre as aprendizagens que transcorrem na sala de aula e nas TE sinalizamos resultados no que se refere às situações-limites e potencialidades de utilizarmos um ambiente multimídia para intensificarmos o diálogo nas disciplinas pedagógicas dos cursos de formação de professores.

As potencialidades, por exemplo, se revelam através do caráter colaborativo que sustenta nossos trabalhos de investigação-ação escolar (IAE) e Educação DialógicoProblematizadora (EDP). Tanto na implementação das aulas quanto nas tarefas de programação e monitoramento das TE no AMEM sempre trabalhamos pelo menos em duplas - professor-doutor responsável pela disciplina (Prof1) mais docente orientada (Prof2) - além do envolvimento de outros sujeitos nos tabalhos (Prof3). Sistematizamos da seguinte forma: (Prof1 + Prof2 + Prof3...).

Nesse sentido, tanto as aulas que exigiram a operacionalização de conhecimentos escolares mais específicos do conteúdo físico envolvido, principalmente as que envolveram resolução de problemas, quanto aquelas que trataram de conhecimentos didáticos foram acompanhadas integralmente pelo professor responsável. Nas TE priorizamos mais os conhecimentos didáticos do que o conhecimento físico-escolar.

Quanto à natureza dos conhecimentos científico-escolares envolvidos nas aulas, ainda destacamos que, por se tratar de uma disciplina com o recorte na Didática da Física, as temáticas das nossas aulas sempre proporcionaram dialogarmos, ao mesmo tempo, sobre os conceitos que são considerados "mais da área educacional" e os da habilitação específica da licenciatura em questão.

As disciplinas da educação somente ganham peso nos sétimo e oitavo (último) semestres do currículo do curso de licenciatura em Física. No sexto semestre, dentre as cinco disciplinas oferecidas, somente a MEN 500 é correspondente à área educacional. Ou seja, após ter concluído mais da metade do curso é que os estudantes iniciam seu contato com os conhecimentos pedagógicos. Isso, muitas vezes, gera muita "resistência" diante da realização das atividades que propomos. 
Nesse sentido, problematizar os conceitos de ambas as áreas nas aulas de MEN 500 tem se tornado boa estratégia para contornar esse problema.

Como se trata de um curso de formação de professores defendemos que as competências e habilidades de ambas as áreas são necessárias. É isso que nem sempre os estudantes compartilham quando se matriculam nas disciplinas do Centro de Educação. Nosso esforço na Didática I foi muito grande para que os estudantes encarassem essa situação como limite e desafiadora na sua formação escolar inicial. $\mathrm{Na} 9^{\mathrm{a}}$ aula nos amparamos principalmente nas diretrizes curriculares nacionais para formação de professores da educação básica e dos cursos de licenciatura em Física para problematizar, com os estudantes, onde e como as políticas públicas educacionais apontam essa necessidade.

Ao monitorarmos as TE no AMEM percebemos que a maioria dos estudantes não estavam contemplando nas respostas os conceitos que nós, professores, esperávamos e havíamos tratado nas aulas. Por isso, trabalhamos na $10^{\mathrm{a}}$ aula com a proposta didático-metodológica da TE no AMEM. Explicitamos como elas se enquadram na espiralização das etapas de programação, ação, observação, reflexão e reprogramação, as quais caracterizam os ciclos da investigação-ação escolar (IAE). Também, explicitamos como as tarefas extra-classe se agrupam com as instâncias de programação e atividade de colaboração no AMEM. Percebemos que a maioria dos estudantes não tinha clareza dos momentos retrospectivos e prospectivos dessas tarefas apesar de termos enfatizado isso, principalmente, nas aulas em que abordamos os conceitos-chave da IAE.

No segundo momento da aula reelaboramos a TE anterior porque o monitoramento das respostas dos estudantes permitiu verificarmos que os principais conceitos trabalhados não haviam sido contemplados.

Ao explicitarmos como implementamos o monitoramento das TE no AMEM (mostrando como temos acesso, por exemplo, aos textos, datas e horários de realização) os estudantes confirmaram, nas suas colocações, que um dos principais limites ocorre por não utilizarem os mecanismos de comunicação do ambiente. Apesar de termos disponíveis ferramentas como mensagens, fóruns, salas de discussão no 
AMEM, quando os estudantes têm dúvidas acabam procurando os professores pessoalmente.

O resultado disso é que, muitas vezes nós professores, não ficamos sabendo das suas principais dúvidas e/ou dificuldades de resolução das tarefas, apesar de termos acesso periódico às respostas, inclusive, para problematiza-las. Isso, acaba prejudicando, também, o diálogo nas aulas.

Mesmo com todo suporte e potencialidades oferecidas pelo AMEM na investigação das TE, a sua realização ainda ocorre a distância. Em muitas situações os estudantes deixam para realizar a tarefa no último período implicando que o professor tenha acesso somente ao produto final. O que quer dizer que os limites para o professor saber das dificuldades que os estudantes enfrentam ainda são muito grandes.

Nesse sentido, podemos afirmar que o êxito no acoplamento entre as aprendizagens presencial e a distância, depende, em grande parte, do trabalho colaborativo (em termos comunicativos) estabelecido entre estudantes e professores no monitoramento das TE e nas aulas. Principalmente, quando se trata de uma disciplina que trata de recortes temáticos tanto da área específica quanto da educação.

Para que isso ficasse claro na MEN 500, principalmente aos estudantes, no início do semestre estipulamos, em conjunto, todas as regras do contrato didático (horários, datas, avaliação, TE, AC, utilização do AMEM, observação nas escolas). Segundo Da Silva (1999) as regras do contrato didático sempre existem e são cumpridas no processo de ensino-aprendizagem mesmo que elas não tenham sido definidas com clareza. O autor afirma que:

O professor cumpre seu contrato dando aulas expositivas e passando exercícios aos alunos; em suas aulas ele deve selecionar partes do conteúdo que o aluno possa aprender e propor problemas cujos enunciados contenham os dados necessários e tão somente esses, cuja combinação racional, aliada aos elementos da aula, permite encontrar a solução do problema. O aluno, por seu lado, cumpre seu contrato se ele bem ou mal compreende a aula dada e consegue resolver, corretamente ou não, os exercícios. (p. 45).

Como nossa perspectiva de trabalho escolar pretende romper com essa estrutura bancária (Freire, 1987), acreditamos ser fundamental que os estudantes compartilhem 
as regras, sabendo, por exemplo que as TE são contempladas no processo de avaliação. Isso pode tornar as aulas e as TE mais colaborativas.

Em alguns momentos esse contrato precisa ser reavaliado, renegociado. A partir da $8^{\mathrm{a}}$ aula passamos a destinar a última meia hora para realizarmos esse diálogo. Mesmo assim, foi necessário destinarmos uma aula para discutirmos específicamente as TE porque nem todos os estudantes tinham uma compreensão clara sobre sua natureza investigativa. O que se deve muito ao fato de virem de uma "prática tradicional em que os problemas estão pré-definidos, pré-determinados. Eles existem nos manuais, nos programas e nos exames. A formulação de problemas não tem lugar, apenas as dúvidas[...]" (Lopes, 2002: 5).

Podemos trazer essas afirmações do autor sobre a prática de ensino de física para prática escolar com as TE. De certa forma, seria no mínimo injusto atribuir somente aos estudantes a responsabilidade pelas dificuldades que estão enfrentando na realização das TE no AMEM. Durante a sua escolaridade essa atividade sempre foi vista como mera tarefa domiciliar e avaliativa, na qual resolvem-se listas de exercícios ou questionários organizados nos livros didáticos.

Dessa forma, quando propomos uma tarefa que exige dos estudantes a construção de um texto argumentativo, no qual formulem uma análise da sua própria formação escolar inicial, de acordo com as políticas públicas educacionais, as situações-limite aparecem.

Nem todas as semanas programamos e disponibilizamos TE, uma vez que defendemos que elas necessitam de programação. Em nenhum momento temos defendido que as TE se tornem "sobra" das atividades que não conseguimos realizar nas aulas. Ao mesmo tempo, ressaltamos que é necessário fazer uma boa avaliação da sua necessidade. Em algumas ocasiões deliberamos (Prof $1+$ Prof 2 + Prof3...) que os principais conceitos já haviam sido abordados nas aulas e evitamos solicitar TE aos estudantes. Também, sempre, levamos em consideração o contexto da formação em que os estudantes estão inseridos. Ou seja, quando os estudantes já possuíam muitas atividades de outras disciplinas, sabíamos que muitos deles não 
priorizariam as tarefas da disciplina de Didática. Não poderíamos exigir condutas dialógicas e comunciativas fora da realidade concreta em que estavam inseridos.

A sistematização, análise e avaliação do trabalho realizado ao longo da docência investigativa na disciplina Didática I da Física (MEN 500) indicou funcionalidades, mas também, situações-limite diante de propostas que pretendem fortalecer condutas mais dialógicas. Ainda precisamos avançar na criação e implementação de estratégias que dêem conta, principalmente, da utilização das ferramentas tecnológicas de interação entre professores e estudantes. No caso do AMEM isso diz respeito, principalmente, aos mecanismos de comunicação que estão em potencial, mas que nem sempre são utilizados para resolver os problemas decorrentes do trabalho escolar.

\section{BIBLIOGRAFIA}

CARR, W. \& KEMMIS, S. Becoming Critical: education, knowledge and action research. The Falmer Press, London, 1986.

DA SILVA, B. A. Contrato Didático. In: Educação matemática: uma introdução. PUC - EDUC, 1999.

DE BASTOS, F. da P. Organização conceitual da melhor solução educacional no momento. UFSM/PPGE, Santa Maria, 2001.

DE BASTOS, F. da P. \& SOUZA, C. A. Estratrégias Didático-Metodológicas no Ensino de Física: RP-IAE no TEIA. Disponível em: http://amem.ce.ufsm.br.

FREIRE, Paulo. Pedagogia do Oprimido. São Paulo. Paz e Terra, 1987.

KEMMIS, S. \& MACTAGGART, R. Cómo planificar la investigación-acción. Editorial Laertes, $3^{\mathrm{a}}$ ed., Barcelona, 1988.

LOPES, B. J. Perspectivar novas modelizações da prática relevantes para o conhecimento profissional do futuro professor de física. Disponível em: http://www.educ.fc.ul.pt/recentes/mpfir/pdfs/bernardinolopes.pdf.

MEC/CNE. Diretrizes Curriculares Nacionais para Formação de Professores da Educação Básica. Brasília/DF, fevereiro de 2002.

MEC/CNE. Diretrizes Curriculares Nacionais para Formação de Professores de Física. Brasília/DF, novembro de 2001.

MEC/SEMTEC. Parâmetros Curriculares Nacionais - Ensino Médio - - Parte III Ciências da Natureza, Matemática e suas Tecnologias. Brasília/DF, 2002. 
MOREIRA, M. A. Ensino de Física no Brasil: retrospectiva e perspectivas.

In: Revista Brasileira de Ensino de Física, v. 22, nº 1, março de 2000.

MÜLLER, F. M. e outros. Ambiente Multimídia para Educação Mediada por

Computador na Perspectiva da Investigação-Ação. FAPERGS, Porto Alegre, RS, 2000.

PAULÚ, N. Cómo ayudarle a su hijo com la tarea escolar. Departamento de Educación de los Estados Unidos, 1988. Disponível em:

<http:/www.ed.gov/pubs/parents/tarea> Acesso: maio de 2002.

PIETROCOLA, M. Identidade, sustentabilidade e visibilidade social da pesquisa em ensino de física. Disponível em:

http://www.sbf1.if.usp.br/eventos/epef/viii/PDFs/MR1_3.pdf.

RODRIGUES, R. M.G. Tarefa de Casa: um dos determinantes do rendimento escolar. In: Revista Educação e Filosofia, v. 12, nº 24, jul/dez, 1998.

ZENTALL, S. \& GOLDSTEIN, S. The importance of homework in your child's education. Disponível em:

http://www.kidsource.com/kidsource/monthly/mon.homework.art.html. 